\title{
Utilization of Modified Rhomboid Flap to Reconstruct Limb Defect after Wide Resection of Large Soft-tissue Sarcoma: Novel Application of an Old \\ Technique
}

Miaomiao Liang

China Medical University First Hospital

Yu Chen ( $\nabla$ toeflmugou@163.com)

China Medial University First Hospital https://orcid.org/0000-0002-6657-3237

\section{Research}

Keywords: Limb salvage, reconstruction, surgical flaps, sarcoma

Posted Date: February 25th, 2020

DOI: https://doi.org/10.21203/rs.2.24458/v1

License: (c) (1) This work is licensed under a Creative Commons Attribution 4.0 International License. Read Full License 


\section{Abstract}

Background: Reconstruction of limb defects following wide resection of large soft-tissue sarcomas (STS) is challenging. Effectiveness of rhomboid flaps in covering these wounds remains to be addressed.

Methods: From March 2018 through February 2019, we utilized modified rhomboid flaps to reconstruct limb defects following wide resection of the large STS ( $\geq 5 \mathrm{~cm}$ in diameter) in 6 patients. There were 3 males and 3 females. The average age was 65 years (47-77 years). Diagnoses included leiomyosarcoma in 3 patients, synovial sarcoma, undifferentiated pleomorphic sarcoma, and myxoid liposarcoma in 1 respectively. The anatomic locations included the anterior knee in 3 cases, upper arm in 2, and thigh in 1. The mean diameter of the tumor measured $10 \mathrm{~cm}(5-17 \mathrm{~cm})$. The mean defect size was $113 \mathrm{~cm} 2(38-270 \mathrm{~cm} 2)$.

Results: The mean follow-up duration was 10 months (range, 6-12 months), no patients were lost to follow-up. Skin grafts were utilized in 2 cases. The mean time to heal was 7 weeks (range, 3-13 weeks). At final follow-up, there were no recurrence and metastasis. One case had cerebral hemorrhage and 1 had wound dehiscence, whereas no reoperation was performed. The range of motion of the joints adjacent to the flap reconstructions were comparable to preoperative status. The mean Musculoskeletal Tumor Society score was 27 (range, 24-30).

Conclusions: The modified rhomboid flap affords great versatility and is easy to design. This technique yields satisfactory effectiveness in reconstructing limb defects after resection of large STS. Long-term studies of large sample size are warranted.

\section{Background}

Soft-tissue sarcomas (STS) comprise heterogeneous malignancies originating from the muscle, fat, blood vessel, nerve, and connective tissue with an incidence of 5 cases per 100,000 inhabitants [1]. The most frequent tumor locations are extremities, and mainstay treatment modality is wide surgical resection with or without medical therapy [2]. Wide resection of large tumors ( $\geq 5 \mathrm{~cm}$ in diameter) in the extremities often leads to exposure of underlying tendons and bones [3-5]. Flap reconstructive procedures are typically warranted for limb-salvage surgery [6].

Various flaps have been advocated to cover the limb defect after wide resection of STS. Free vascularized flaps are frequently utilized, including the latissimus dorsi flap, anterolateral thigh flap, rectus abdominis flap, etc [6, 7]. The limb-salvage rate was as high as $90 \%[6,7]$. However, microvascular procedures usually require a plastic surgeon, and can be hardly performed by orthopedic oncologists. Although local flaps and pedicled musculocutaneous flaps are technically easier, these procedures are still restricted for coverage of large limb defects due to significant local tension [8]. Some flap designs are difficult to learn [8]. Because limb STS dictates multidisciplinary management and are primarily treated by orthopedic oncologists, flap reconstructive procedures that yield favorable efficiency and moderate difficulty are warranted to simplify the surgical procedures.

The rhomboid flap (RF) was initially introduced by Limberg, and modified by Dufourmentel $[9,10]$. The traditional RF is a local flap designed in compliance with the parallelogram principle (Fig. 1). It proved to be an effective procedure for wound closure in the torso [11]. Although the RF and its variations are popularized, its effectiveness in reconstructing the limb defect has been rarely addressed. The traditional procedure tailors a circular defect into a rhomboid wound which necessitate sacrifice of circumferential tissue, this may increase the local tension and entail higher difficulty for reconstruction of the limb wound. Thus, we designed a modified RF to facilitate this procedure and conducted preliminary evaluation of its effectiveness in reconstructing the limb defect after wide resection of large STS. The relevant technical points were also summarized.

\section{Methods}

General data of the patients

From March 2018 through February 2019, we utilized modified RF to reconstruct limb defects following wide resection of the large STS ( $\geq 5 \mathrm{~cm}$ in diameter) in 6 patients (Table 1). There were 3 male cases and 3 female cases. The average age was 65 years (47-77 years). Diagnoses included leiomyosarcoma in 3 patients, synovial sarcoma, undifferentiated pleomorphic sarcoma, and myxoid liposarcoma in 1 respectively. The anatomic locations included the anterior knee in 3 cases, upper arm in 2, and thigh in 1 . The mean diameter of the tumor measured $10 \mathrm{~cm}(5-17 \mathrm{~cm})$. The mean defect size was $113 \mathrm{~cm}^{2}(38-$ $270 \mathrm{~cm}^{2}$ ). In accordance with the American Joint Committee on Cancer (AJCC) staging system, 5 cases had stage IIB tumor, whereas 1 had IIA [12]. Limb functions were assessed by range of motion (ROM) of the joints and the Musculoskeletal Tumor Society (MSTS) score [6]. One patient had undergone a previous surgery, whereas no case had received neoadjuvant radiotherapy and chemotherapy. 
Table 1

Characteristics of the patients

\begin{tabular}{|c|c|c|c|c|c|c|c|c|c|c|c|c|c|}
\hline $\begin{array}{l}\text { No. } \\
\text { Cases }\end{array}$ & Sex & $\begin{array}{l}\text { Age } \\
\text { (v) }\end{array}$ & Locations & Diagnosis & $\begin{array}{l}\text { AJCCe } \\
\text { Stage }\end{array}$ & $\begin{array}{l}\text { Tumor } \\
\text { Diameter } \\
\text { (cm) }\end{array}$ & $\begin{array}{l}\text { Defect } \\
\text { Size } \\
\left(\mathrm{cm}^{2}\right)\end{array}$ & $\begin{array}{l}\text { Previous } \\
\text { surgery }\end{array}$ & $\begin{array}{l}\text { Full } \\
\text { thickness } \\
\text { skin graft }\end{array}$ & $\begin{array}{l}\text { Time } \\
\text { to } \\
\text { heal } \\
\text { (week) }\end{array}$ & $\begin{array}{l}\text { Follow- } \\
\text { up } \\
\text { (month) }\end{array}$ & Complication & Survival \\
\hline 1 & M & 77 & $\begin{array}{l}\text { Upper } \\
\text { arm }\end{array}$ & $\mathrm{LS}^{\mathrm{a}}$ & IIB & 8 & 71 & -- & -- & 3 & 7 & $\begin{array}{l}\text { Cerebral } \\
\text { Hemorrhage }\end{array}$ & $\begin{array}{l}\text { Disease } \\
\text { free }\end{array}$ \\
\hline 2 & $\mathrm{~F}$ & 63 & Thigh & $S S^{b}$ & IIB & 7 & 64 & -- & -- & 5 & 13 & - & $\begin{array}{l}\text { Disease } \\
\text { free }\end{array}$ \\
\hline 3 & M & 68 & $\begin{array}{l}\text { Upper } \\
\text { Arm }\end{array}$ & UPS ${ }^{\mathrm{C}}$ & $\| \mathrm{A}$ & 5 & 38 & -- & -- & 3 & 12 & - & $\begin{array}{l}\text { Disease } \\
\text { free }\end{array}$ \\
\hline 4 & $\mathrm{~F}$ & 72 & $\begin{array}{l}\text { Anterior } \\
\text { Knee }\end{array}$ & LS & IIB & 9 & 130 & -- & -- & 13 & 12 & $\begin{array}{l}\text { Wound } \\
\text { dehiscence }\end{array}$ & $\begin{array}{l}\text { Disease } \\
\text { free }\end{array}$ \\
\hline 5 & $M$ & 47 & $\begin{array}{l}\text { Anterior } \\
\text { Knee }\end{array}$ & LS & IIB & 12 & 102 & -- & Yes & 8 & 8 & - & $\begin{array}{l}\text { Disease } \\
\text { free }\end{array}$ \\
\hline 6 & $\mathrm{~F}$ & 63 & $\begin{array}{l}\text { Anterior } \\
\text { Knee }\end{array}$ & $M^{d} S^{d}$ & IIB & 17 & 270 & Yes & Yes & 9 & 6 & - & $\begin{array}{l}\text { Disease } \\
\text { free }\end{array}$ \\
\hline
\end{tabular}

Table 2

Functional outcome

\begin{tabular}{|llll|}
\hline No. Cases & Preop ROM $^{\text {a }}$ & Postop ROM & N/A \\
\hline 1 & N/A ${ }^{\text {b }}$ & Hip: flexion $100^{\circ}$; abduction $35^{\circ}$; adduction $30^{\circ}$ \\
\hline 2 & Hip: flexion $110^{\circ}$; abduction $35^{\circ}$; adduction $30^{\circ}$ & Elbow: $0^{\circ}-130^{\circ}$ \\
\hline 3 & Elbow: $0^{\circ}-135^{\circ}$ & Knee: $0^{\circ}-115^{\circ}$ \\
\hline 4 & Knee: Knee: $0^{\circ}-120^{\circ}$ & Knee: $0^{\circ}-120^{\circ}$ \\
\hline 5 & Knee: $0^{\circ}-125^{\circ}$ & $0^{\circ}-70^{\circ}$ \\
\hline 6 & Knee: $0^{\circ}-90^{\circ}$ & 25 \\
\hline $\begin{array}{l}\text { a: ROM range of motion of the joints adjacent to the flap reconstructions; b: N/A denotes not available; c: MSTS denotes Musculoskeletal Tumor Society } \\
\text { score }\end{array}$
\end{tabular}

Wide resection of the tumor

The tumor size, depth, and magnitude of resection were determined in compliance with contrast-enhanced magnetic resonance images (MRI). Intraoperatively, the tumor was resected in combination with a $2-3 \mathrm{~cm}$ cuff of normal tissue. Intraoperative frozen section examination verified negative margins. The procedure resulted in exposure of underlying tendons and bones in 3 cases with anterior knee lesions. In these cases, after resecting the periosteum and partial retinaculum, $95 \%$ ethanol was applied to the wound for 30 minutes for further devitalization, so as to reduce the risk of recurrence.

Modifications to the classical RF

All cases had primary wound closure with use of the modified RF. Preoperative hand-held Doppler examination localized perforators, which were included in the flap design. We modified the classical RF (Fig. 1) by using the curved defect border as a side of the flap (Fig. 2-A). The diameter of the circular defect and the shorter axis of the elliptical defect are extended to the neighboring tissue, and equates the length of the extended line (Fig. 2-A, line $A B=$ line $B C)$. An angle of approximately $60^{\circ}$ (or slightly less than $60^{\circ}$ ) is drawn at the end of the extended line (Fig. 2-A, $\angle B C D$ ), with the other side of the angle going in parallel with the defect border (Fig. 2-A, curved line CD). The length of both sides of the angle are (or approximately) equal. Wound closure results in a zigzag incision similar to the traditional RF (Fig. 1-C, Fig. 2-C).

Use of the modified RF for coverage of the limb defect

In the extremities, the direction of the vector of tension in the flap and location of the incisions must be properly designed. There are two vectors of tension in our flap. One vector runs horizontal to the imaginary line $A^{\prime} B$ of the defect (Fig. 2-B, V1), the other lies at approximately a $60^{\circ}$ angle to the line BC (Fig. 2-B, V2). Therefore, the sum of the vector of stress runs at about a $30^{\circ}$ angle to the line BC (Fig. 2-B, Vt). The vector of tension in the flap is designed approximately in parallel with the long axis of the extremity. At least two of the incisions are placed in the relaxed skin tension lines (RSTL), and vertical crossing of the joint line is avoided. These principles entail minimum tension of the flap and preservation of the limb function (Fig. 3).

Postoperative management 
Intravenous antibiotics (cefazolin, $3 \mathrm{~g}, 1 / 8 \mathrm{~h}$ ) were applied for 7 days. Drain was removed when the output was less than $20 \mathrm{ml} / \mathrm{d}$. Active joint exercise was allowed at 6 weeks postoperatively. Follow-up was every 3 months for the first 2 years, 4 months the third year, 6 months the fourth and fifth year, and annually thereafter. All cases received physical examination, lung computerized tomography (CT) and MRI assessment of the operated locations. In this case series, no patients received postoperative radiotherapy and chemotherapy.

\section{Results}

The mean follow-up length was 10 months (range, 6-12 months) (Table 1). No patients were lost to follow-up. The mean time to heal was 7 weeks (range, 313 weeks). Full-thickness skin grafts were utilized in 2 cases. At final follow-up, there were no recurrence and metastasis. All patients were satisfied with the appearance of the operated locations. There were no flap failure, infection, and seroma. One case had cerebral hemorrhage and 1 had wound dehiscence, whereas no case needed reoperation. The patient who had the cerebral vascular accident was not included in the functional evaluation. The ROM of the joints adjacent to the flap reconstructions were comparable to preoperative status (Table 2). The mean MSTS was 27 (range, 24-30) (Table 2).

\section{Discussion}

Wide resection of the large STS in the extremities usually leads to exposure of underlying tendons, bones, and neurovascular bundles. To achieve limb salvage, flap reconstructions are typically warranted. The RF was firstly described by Limberg and has been popularized for wound closure [13-16]. This technique proved to be effective for coverage of torso defects, such as pilonidal sinus disease and facial wounds [13-16]. However, studies focusing on the use of RF for reconstruction of limb defects are sparse. The traditional RF necessitated further resection of the circumferential tissue to create a rhomboid wound, which allowed the flap to fit the defect snugly [17-19]. However, this procedure entails higher skin tension in the extremities. Although its variations allowed for easier closure of the wound, the geometric design was difficult to learn [20,21].

We propose a modification to the classical RF. Regardless of the defect shape (circular or elliptical), we design a rhomboid-like flap sharing the curved border with the defect, hence it's unnecessary to tailor the wound further. In the classical flap, there are two points that are in strongest tension (Fig. 1-B, points a and D), and the flap fits the defect snugly, this increases the difficulty of wound closure since the versatility of the flap is restricted [22, 23]. In our flaps, one of the points under greatest tension (Fig. 2-B, point a) can be matched to any points on a length of the defect border (Fig. 2-B, dotted line A'), hence the flap affords more versatility. Additionally, due to preservation of the circumferential tissue, the advancing distance of the flap is reduced (Fig. 2-B, imaginray line $A^{\prime} B$ ). All these factors allow easier closure of the wound. For large defects, we also slightly reduced the $60^{\circ}$ flap angle, so as to further reduce the skin tension [24-26].

The design of RF is critical. We took into account of the tumor size, the perforator, limb axis, RSTL, local tension, and joint motion before flap design. The vector of stress in the flap is placed in parallel with the limb axis. At least two of the incisions are placed in the RSTL, and no incisions cross the joint line vertically. After dissection of the flap, the two points under strongest tension should be sutured firstly, so as to avoid repeated traction of the flap [27, 28]. Our flaps are easier to draw compared with the classical RF and its variations. The round and oval defects slightly decrease the advancing distance of the flap and adds its versatility. The procedure is easy to learn and viable for orthopedic oncologists.

The importance of functional outcome after limb-salvage surgery for STS has been increasingly recognized [1, 4]. The postoperative limb function is associated with various factors, such as the magnitude of resection, tumor location, and reconstructive procedures [18]. A systematic review analyzed the outcomes after functioning reconstructions in the treatment of limb STS, the results indicated most patients achieved favorable functional outcomes [18]. A case-control propensity score analysis suggested flap reconstruction tended to secure a wider surgical margin, whereas the MSTS score was lower than those having primary closure [3]. In this case series, the modified RF resulted in favorable functionality. However, it's noteworthy we did not perform muscle transfer and reconstruction of the tendons and the nerves, these procedures may affect the functional outcome.

Our research is subject to the limitations of the single-center retrospective study. Due to the limited sample size, a control group in comparison with our flaps was impossible. Prospective case-control studies are warranted to demonstrate the effectiveness of the modified RF in treatment of limb defects following wide resection of the large STS.

\section{Conclusions}

The modified RF is versatile, easy to design and yields satisfactory effectiveness in treatment of limb defects after resection of large STS. In the extremities, flap designing is dependent upon the limb axis, perforator, RSTL, skin tension, and joint motion. Yet to be evaluated in long-term studies of larger sample size, we believe our flap provides a valuable option for reconstruction of large limb defects after resection of the STS.

\section{List Of Abbreviations}

STS: soft tissue sarcoma; AJCC: American Joint Committee on Cancer; MRI: magnetic resonance images; RSTL: relaxed skin tension lines; RF: rhomboid flap; MSTS: Musculoskeletal Tumor Society

\section{Declarations}

Ethics approval and consent to participate: This study was approved by the Ethics Committee of First Hospital of China Medical University (Number AF-0G-031) and informed consent was waived due to the retrospective nature of this study.

Consent for publication: All the images used in this article were completed following obtaining a written consent for publication from each patient. 
Availability of data and materials: The datasets used and/or analyzed during the current study are available from the corresponding author on reasonable request.

Competing interests: The authors declare they have no competing interests.

Funding: There has been no funding for this study.

Authors' contributions: YC accountable for design of the study and writing of the manuscript. MML accountable for the collection and analysis of the data. All authors read and approved the final manuscript.

Acknowledgements: The authors would like to thank all participating patients and colleagues who made this study possible.

\section{References}

1. Kneisl JS, Coleman MM,Raut CP: Outcomes in the management of adult soft tissue sarcomas. J Surg Oncol 2014; 110(5): 527-38.

2. Park JW, Yoo HJ, Kim HS, Choi JY, Cho HS, Hong SH,Han I: MRI surveillance for local recurrence in extremity soft tissue sarcoma. Eur J Surg Oncol 2019; 45(2): 268-74.

3. Kang S, Han I, Kim S, Lee YH, Kim MB,Kim HS: Outcomes after flap reconstruction for extremity soft tissue sarcoma: a case-control study using propensity score analysis. Eur J Surg Oncol 2014; 40(9): 1101-8.

4. Kask G, Barner-Rasmussen I, Repo JP, Kjaldman M, Kilk K, Blomqvist C,Tukiainen EJ: Functional Outcome Measurement in Patients with Lower-Extremity Soft Tissue Sarcoma: A Systematic Literature Review. Ann Surg Oncol 2019;

5. Duran-Moreno J, Kontogeorgakos V,Koumarianou A: Soft tissue sarcomas of the upper extremities: Maximizing treatment opportunities and outcomes. Oncol Lett 2019; 18(3): 2179-91.

6. Bridgham KM, El Abiad JM, Lu ZA, Bhat D, Darrach H, Morris CD, Levin AS,Sacks JM: Reconstructive limb-salvage surgery after lower extremity soft tissue sarcoma resection: A 20-year experience. J Surg Oncol 2019; 119(6): 708-16.

7. Geller DS, Hornicek FJ, Mankin HJ,Raskin KA: Soft tissue sarcoma resection volume associated with wound-healing complications. Clin Orthop Relat Res 2007; 459(182-5.

8. Kadle R, Motosko CC, Zakhem GA, Stranix JT, Rapp T,Saadeh PB: Flap Reconstruction of Sarcoma Defects in the Setting of Neoadjuvant and Adjuvant Radiation. J Reconstr Microsurg 2019; 35(4): 287-93.

9. Limberg AA: Design of local flaps. Mod Trends Plast Surg 1966; 2(38-61.

10. Dufourmentel C: [The L-shaped flap for lozenge-shaped defects. Interview with Claude Dufourmentel by E. Achard]. Ann Chir Plast 1979; 24(4): 397-9.

11. Imafuku K, Hata H, Yamaguchi Y, Inamura Y, Kitamura S, Yanagi T,Shimizu H: Modified Dufourmentel flap, easy to design and tailor to the defect. J Dermatol 2017; 44(1): 68-70.

12. Edge SB, Compton CC: The American Joint Committee on Cancer: the 7th edition of the AJCC cancer staging manual and the future of TNM. Ann Surg Oncol 2010; 17(6): 1471-4.

13. Sisti A, Tassinari J, Milonia L, Grimaldi L,Nisi G: Limberg Flap for Surgical Treatment of Melanoma. Plast Reconstr Surg 2016; 138(3): 565e-6e.

14. Uzun H, Bitik O, Kamburoglu HO, Dadaci M, Calis M,Ocal E: Assessment of Patients Who Underwent Nasal Reconstruction After Non-Melanoma Skin Cancer Excision. J Craniofac Surg 2015; 26(4): 1299-303.

15. Skiles MS, Chaglassian TA: Resurfacing facial defects using the Limberg flap. Clin Bull 1977; 7(4): 149-53.

16. Faenza M, Pieretti G, Lamberti R, Di Costanzo P, Napoletano A, Di Martino M, Casale F, Ferraro GA,Nicoletti GF: Limberg fasciocutaneous transposition flap for the coverage of an exposed hip implant in a patient affected by ewing sarcoma. Int J Surg Case Rep 2017; 41(516-9.

17. Hanada M, Kadota H, Yoshida S, Takeuchi N, Okada T, Matsumoto Y,Nakashima Y: Large-defect Resurfacing: A Comparison of Skin Graft Results Following Sarcoma Resection and Traumatic Injury Repair. Wounds 2019; 31(7): 184-92.

18. Martin E, Dullaart MJ, van de Sande MAJ, van Houdt WJ, Schellekens PPA, Coert JH, Berner JE, Troisi L,Wilson P: Resuscitating extremities after soft tissue sarcoma resections: Are functional reconstructions an overlooked option in limb salvage? A systematic review Eur J Surg Oncol 2019; 1532-2157 (Electronic)):

19. Berner JE, Troisi L,Wilson P: Successful salvage of failed post-sarcoma excision reconstruction and exposed alloplastic mesh with an anterolateral thigh flap. Arch Plast Surg 2019; 46(4): 390-1.

20. Sebastian M, Sroczynski M,Rudnicki J: The Dufourmentel modification of the limberg flap: Does it fit all? Adv Clin Exp Med 2017; 26(1): 63-7.

21. Yabanoglu H Fau - Karagulle E, Karagulle E Fau - Belli S, Belli S Fau - Turk E,Turk E: Results of modified Dufourmentel rhomboid flap in patients with extensive Sacrococcygeal pilonidal disease. Acta Chir Belg 2014; 114(1): 52-7.

22. Jabbar MS, Bhutta MM,Puri N: Comparison between primary closure with Limberg Flap versus open procedure in treatment of pilonidal sinus, in terms of frequency of post-operative wound infection. Pak J Med Sci 2018; 34(1): 49-53.

23. Kaplan M, Ozcan O, Bilgic E, Kaplan ET, Kaplan T,Kaplan FC: Distal scar-to-midline distance in pilonidal Limberg flap surgery is a recurrence-promoting factor: A multicenter, case-control study. Am J Surg 2017; 214(5): 811-9.

24. Chaubey D, Kumar V, Thakur VK, Yadav R, Hasan Z, Prasad R,Rahul SK: Wound Closure in Large Neural Tube Defects: Role of Rhomboid Flaps. J Cutan Aesthet Surg 2019; 12(2): 124-7.

25. Yildiz T, Ilce Z,Kucuk A: Modified Limberg flap technique in the treatment of pilonidal sinus disease in teenagers. J Pediatr Surg 2014; 49(11): 1610-3.

Page 5/8 
26. Kaya B, Eris C, Atalay S, Bat O, Bulut NE, Mantoglu B,Karabulut K: Modified Limberg transposition flap in the treatment of pilonidal sinus disease. Tech Coloproctol 2012; 16(1): 55-9.

27. Altun S, Cakir F, Oztan M, Okur MI,Bal A: Do rhomboid flaps provide more elongation than Z-plasty flaps? An experimental study. J Plast Surg Hand Surg 2018; 52(3): 148-52.

28. Hung MH, Liao CT, Kang CJ,Huang SF: Local Rhomboid Flap Reconstruction for Skin Defects After Excising Large Parotid Gland Tumors. J Oral Maxillofac Surg 2017; 75(1): 225.e1-.e5.

\section{Figures}

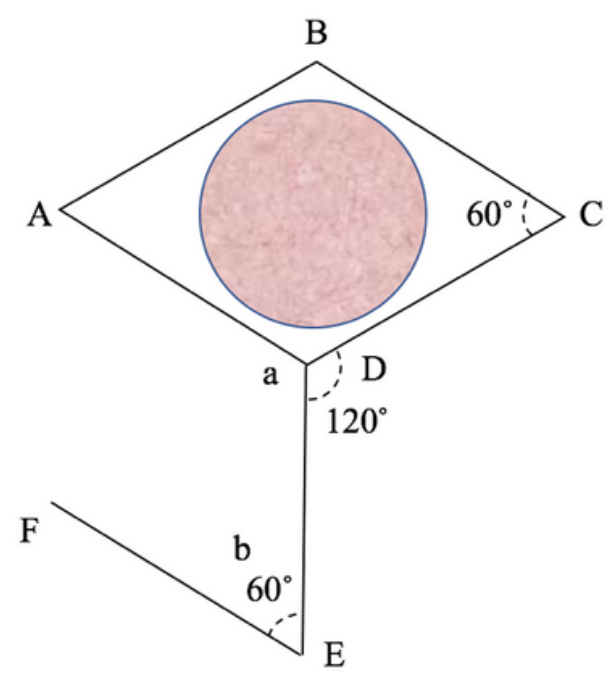

A

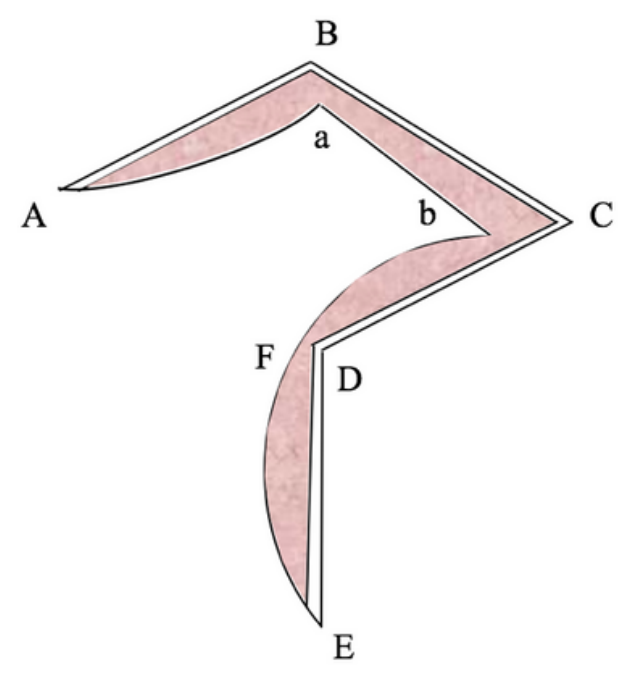

B

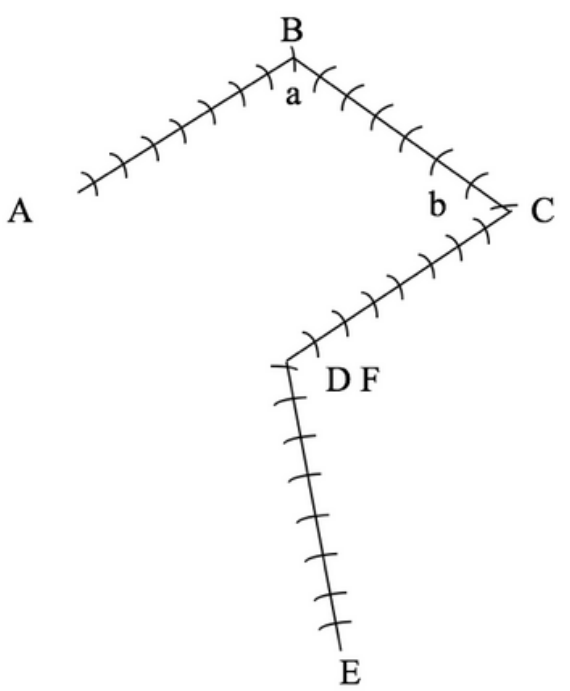

$\mathrm{C}$

\section{Figure 1}

Traditional rhomboid flap. Demonstration of the traditional rhomboid flap. Figure 1-A shows the geometric design of the flap, the circular defect is tailored into a parallelogram with $\angle B C D=\angle D E F=60^{\circ}$, line $A D=$ line $A B$, line $D E=$ line $B C$, and line $E F=$ line $C D$; Figure 1-B demonstrates intraoperative transfer of the flap, and $1-\mathrm{C}$ shows the zigzag-shaped incision. 


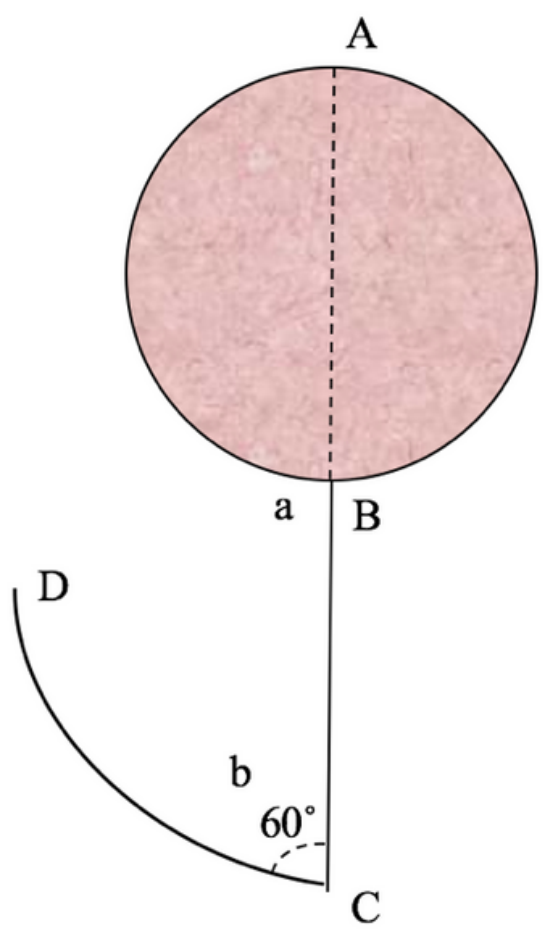

A

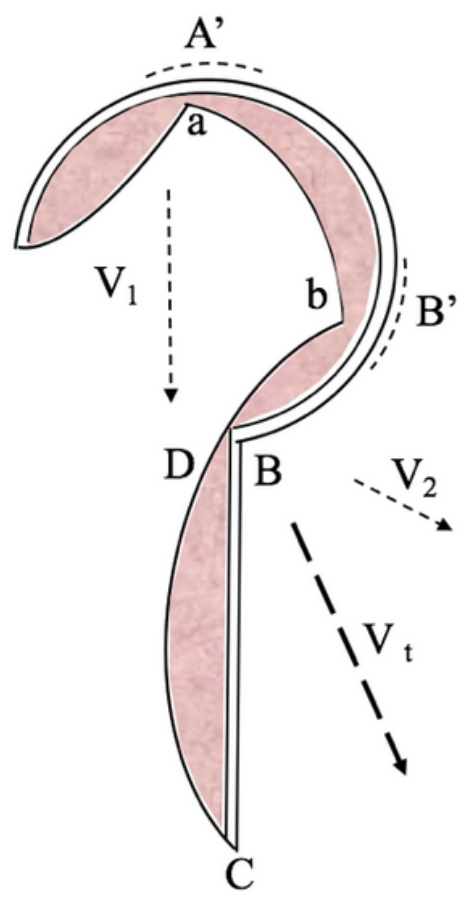

B

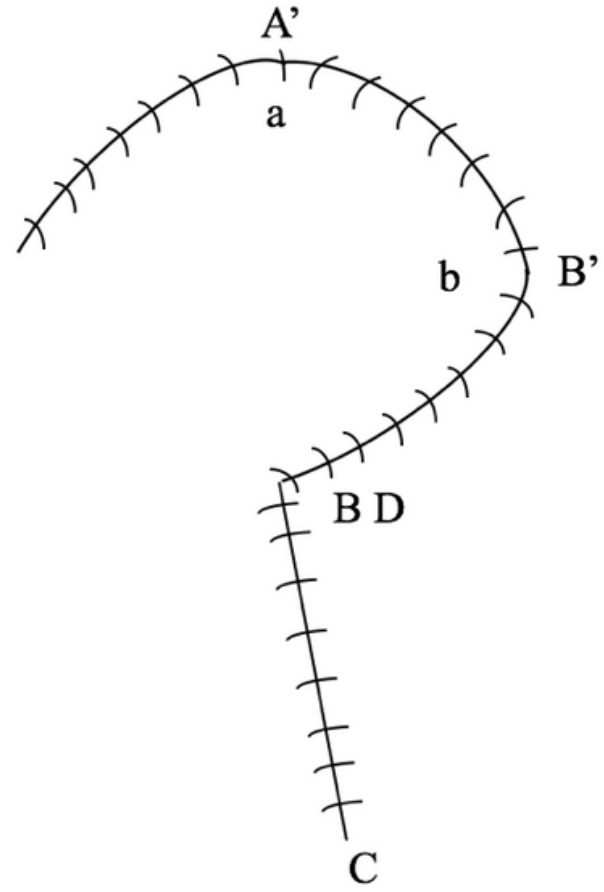

C

Figure 2

Modified rhomboid flap. Demonstration of the modified rhomboid flap. Figure 1-A shows the geometric design of the flap, the dotted line $A B$ is the diameter (or the shorter axis) of the defect after resection of the superficial soft tissue sarcoma, line $A B$ is extended to $C$ with line $A B=$ line $B C, \angle B C D=60^{\circ}$ (or slightly $\angle 60^{\circ}$ ), line $C D$ runs in parallel with the contralateral border of the flap; Figure 1-B shows intraoperative transfer of the flap, the points a and $B$ are in strongest tension, there're two vectors of tension, one runs horizontal to the imaginary line $A^{\prime} B(V 1)$, and the other lies at approximately a $60^{\circ}$ angle to the line $B C(V 2)$, hence the sum of the vector of tension runs at about a $30^{\circ}$ angle to the line $\mathrm{BC}(\mathrm{Vt})$, points a and b of the flap are matched to any point in the curved line $\mathrm{A}^{\prime}$ and $\mathrm{B}^{\prime}$; Figure 1-C shows the incisions of the flap. 


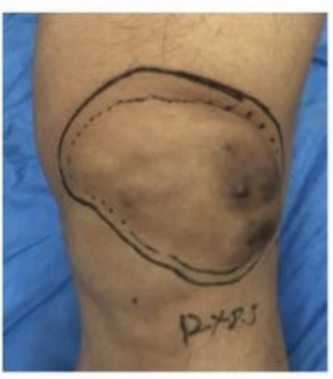

A

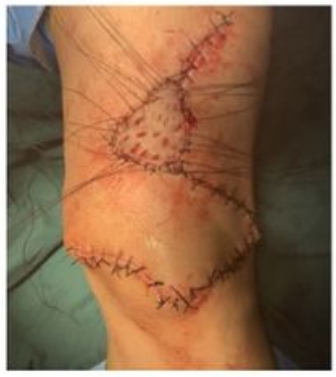

F

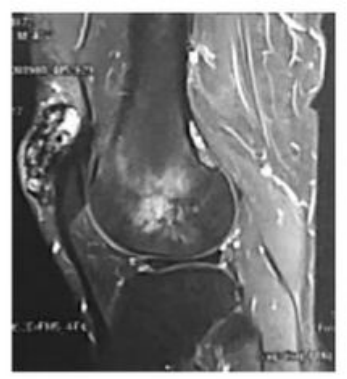

B

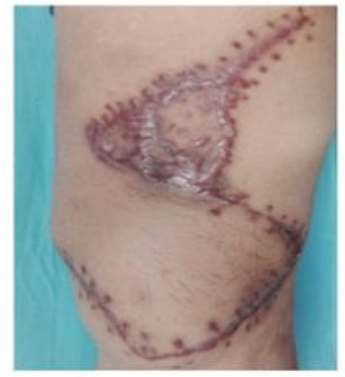

G

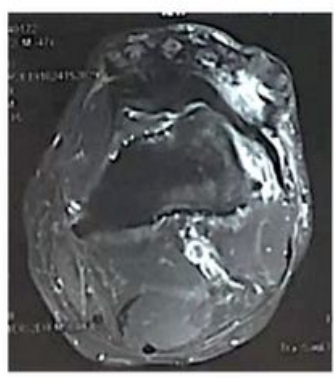

C

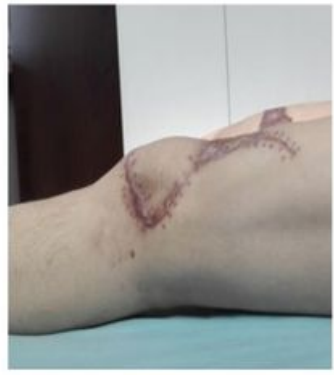

$\mathrm{H}$

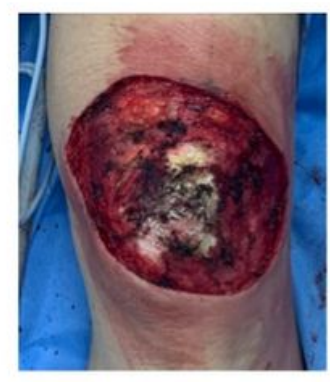

D

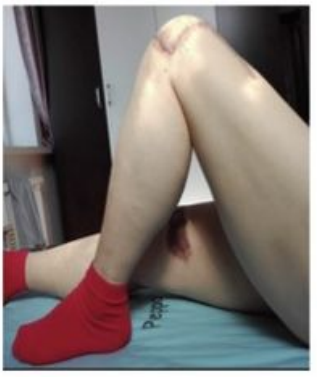

I

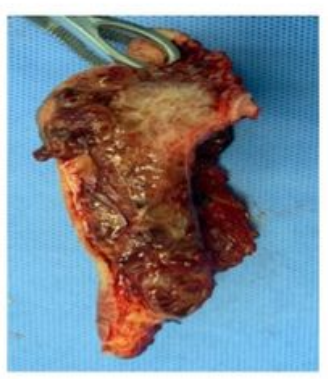

E

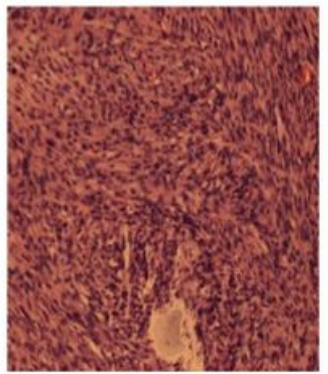

J

\section{Figure 3}

Reconstruction of the defect following resection of the leiomyosarcoma in the anterior knee. Figure 3-A shows the appearance of the tumor located at the left anterior knee of a 47-year old male patient; Figure 3-B and C: T2 weighted MRI demonstrates the size and the depth of the tumor; Figure 3-D shows the wound following wide resection that resulted in exposure of the underlying bone and tendons, whereas E demonstrates the gross specimen; Figure 3-F and $\mathrm{G}$ demonstrate the modified rhomboid flap and full-thickness skin graft. Figure 3-H and I show the range of motion of the knee was favorable. Figure 3-J shows the histologic finding indicative of leiomyosarcoma $(\mathrm{HE}, \times 100)$. 